\title{
1. Marketing rural tourism: experience and enterprise
}

This work seeks to disrupt the traditional notion of marketing that has long been understood as composite of arsenal unique to the marketer. Instead, the emphasis is on varying, individually distinct encounters and contexts that engender varied readings of places and people by sensually engaging the body. As actors become "containers' ${ }^{1}$ of the rural milieu, often considered a static repository of tradition, norms and values - a bona fide nucleus - and consequently a key site for the (re)discovery of authentic place identity, attention is on facets of rurality emerging experientially from relational/discursive encounters. Rurality is fluid (after Massey, 1995) and even while the surface materiality of a rural locality remains the same, its complexion is aligned with the identity/experiences of people inhabiting/visiting it, or vice versa (Gray, 1999). Sutherland and Acord (2007) argue that "every individual "writes" social realities, as well as being educated within them' (p. 135). Indeed, the authentic persona of rurality, key merchandise in packaging and marketing the consumption experience of rural:

is not only embedded within the social realm, but is also subjective. This is because assessments of the authenticity of objects or experiences are based on assumptions of perceived essence ... not reliant on whether the experience is really authentic, but instead on . . . subjective assessment that allows individuals to overlook or downplay the inauthentic elements in many consumption experiences; such as ... the staged authenticity of museums ... (Hall, 2010, p. 265)

In fact, such an authentication process stems from and is accompanied by visitors' quest for experiences (see Box 1.1 for industry perspectives) that help them (re)construct or reinforce particular identities or personal histories and allow an opening of the imagination beyond the usual preconceived categories into which much of daily life is organised. Experience as a key word is beginning to influence rural tourism policymaking. For instance, Tourism Australia, the agency responsible for promoting Australia, targets the 'International Experience Seeker' segment in its marketing strategy for selling the cultural and natural appeal of the Australian Alps (Tourism Australia, 2010). The aim is to: 
populate Brand Australia with world class visitor experiences that draw on the landscape's nature and culture to appeal to the Experience Seeker . . . Less than $10 \%$ of Australian Alps visitors are Experience Seekers yet they currently represent about $60 \%$ of Australia's inbound market. They stay longer, have a higher than average spend and represent a growth opportunity. (Tourism Australia, 2010, p. 3)

\section{BOX 1.1 MARKETING 'EXPERIENCE': INDUSTRY PERSPECTIVES}

\section{'Experience' tourism to shape the future of travel}

Increasing numbers of people will look for 'life experiences' as the lure of the beach continues to fade. The age of the Internet and satellite television is fuelling people's desires to travel further afield and to experience different cultures. There is so much information and so many programmes covering all different parts of the world. People are looking for life experiences to satisfy their curiosity. They tell us they've had enough of the more accepted form of holiday of going to a beach and being herded around on a package deal. Even families with young children are turning to adventure, while parents with 16-year-olds are using adventure as a 'bonding experience'. (Nigel Gifford, managing director of Adventure tour operator High and Wild)

There is growing phenomenon of travel products such as archaeology digs, learning a foreign language and cookery, but people do still want the beach. (Cendant chief Operating officer Chris Vukelich)

Source: TravelMole, Report by Steve Jones, Wednesday, 21 September 2005.

Our visitors want and expect more from their time away. They do not simply want to see things; they want to be engaged and they want to immerse themselves in the places they visit. What this means is a change of focus. To truly engage with our visitors we must shift our thinking and connect with them on a deeper, more personal level. Visitors want to feel something from the places they visit, they want to be touched by the stories of the people and actively participate in culture and community. We are no longer selling visitors a 'product' - we are selling them authentic experiences of Northern Ireland.

Source: Tourism Northern Ireland, 2014, www.nitb.com.

To capture the experience of seekers who often travel off the beaten track and are quick to experiment, the strategy aims to deliver 'signature' or lead experiences that are not only engaging, inspiring and sustainable, but also distinctive and authentic. Similarly, in Europe, the emphasis is on the provision of sustainable and innovative transnational thematic rural tourism products that enhance the 
visibility of cultural routes and small, non-traditional destinations (COM (2010)/352, 2010).

Thus the emphasis of this text is on outlining the materiality of experiences rurality offers and actors' enterprise in conveying the real/symbolic value embedded within them. At the heart of the discussion presented in this work is a concern with the interplay between visitors' consumption experience and different components of rurality, shaped and reworked by providers' ingenuity and sociality, enacted in tandem with their everyday practices. Also, whilst this work moves away from Pine and Gilmore's (1999) focus on supplier-led experiences 'staged' for largely passive audiences through its emphasis on tourists' creative agency in (re)shaping the 'experienced realities' at a place, it retains their attention on the significance of compelling narratives in delivering opportunities for sensory stimulus and engagement.

\section{RESEARCH CONTEXT}

A key component of this work is its engagement with endogenous practices and actors' narratives underlying innovative forms of rural tourism experience and enterprise which is materially and discursively embedded in rural peculiarities. From a marketing perspective it implies being cognisant of variable and plural pathways to creating aesthetically pleasing encounters with the 'rural' and the enterprise involved in meaning-construction and provision of interpretation. Since most tourism texts tend to bypass the nuances inherent in rural tourism marketing or 'dialogical ontology' (see Bakhtin, 1981) - a rich interweave of ongoing narratives - defining place appeal and dynamism, this work intends to open up debate into actors' agency and their narrative capacities in delivering memorable experiences and combating 'market resistance' (e.g. non-purchase/lack of consumer interest). The book considers rural tourism marketing as a variegated phenomenon linked intricately with how rurality is experienced and shaped by actors' enterprise and a broad array of socio-cultural, political, economic and material processes and practices. Whilst Franklin (2003) situates tourism as a central social occurrence alongside work and routine, I take this a step further by positioning the marketing of it as a channel to serve local needs, '. . . an activity whose net developmental impact on rural people is positive' (Modi, 2009, p. 100). In fact, my approach to rural tourism marketing is focused on assaying its capabilities in depicting local essence, augmenting residents' well-being and addressing tourist sensibilities. Overall, the book seeks to complement studies on tourist experience (Filep and 
Pearce, 2014; Sharpley and Stone, 2011; Suvantola, 2002) and tourism enterprise (Getz and Carlsen, 2005; Leslie, 2014) and builds upon my own work on Integrated Rural Tourism (IRT) (Saxena et al., 2007). Although individual chapters follow a distinctive line of enquiry, they all are underpinned by a focus on the extent to which rural tourism marketing reflects aspects of how rurality is experienced and lived and the complex socioeconomic circumstances shaping actors' entrepreneurial aspirations. In fact, illustrative examples of how dominant, residual and emergent forms of rurality ${ }^{2}$ are (re)presented and marketed act as routes for mapping their practical and symbolic value as well as the profile of those engaged in their packaging and promotion.

Also, a key focus is on how an accent on the assertion of the 'value of ordinary rural lives' in marketing parlance works to secure the role of local mores, voices and flavour in simultaneously defining the product and (de)constructing 'rural' as the site of exclusion from and construed in opposition to the dominant national culture (see Chapter 3 for details). In theorising the politics of place marketing (see Chapter 3), I examine how marketing and promotion of the 'rural' ushers it into urban settings through the process of disembeddedness revealing commodified rurality's social reach and cultural penetration (see Chapter 2). As such, this study uses the marketing of rurality (see Chapter 2) as a lens through which to also take account of issues such as (dis)empowering place politics (Chapter 3), the market orientation of rural tourism firms (Chapter 4), the profile of rural tourists (see Chapter 5) and residents' worldviews (see Chapter 6). To bring individual chapters together, and to explore their underlying themes in a more overt manner, the final chapter considers the implication of transition from a routine of production/consumption of commodities (natural/built) to the increasing ascendancy on production/consumption of 'experiences' for rural tourism enterprise (see Chapter 7). Broadly, in organising the content of individual chapters I draw upon the key tenets of IRT (see Table 1.1) that allow an assessment of environmental, economic, socio-cultural and political dimensions integral to shaping rural destinations' distinctive image, product development and the associated experiences visitors are likely to encounter.

In examining these dimensions, my focus is on actors' narratives ${ }^{3}$ (see Gubrium and Holstein, 2001; Labov, 1982; Labov and Waletzky, 1967) that allow an insight into the storytellers' everyday routines, collective values and tacit sociality which provide the props enabling '.. both narrators and listeners to place actions, motives, personal evaluations and outcomes in a particular context' (Slobin, 1998, p. 365). A narrative perspective is particularly useful as there are significant differences between 


\section{Table 1.1 Dimensions of IRT in marketing rural tourism}

\begin{tabular}{|c|c|}
\hline Key tenets of IRT & Implications for rural tourism marketing \\
\hline Networks & $\begin{array}{l}\text { The ability of individuals, firms and agencies in a given } \\
\text { locality and beyond to work together to develop and } \\
\text { manage rural tourism marketing }\end{array}$ \\
\hline Scale & $\begin{array}{l}\text { The extent of marketing's spread and distribution in a } \\
\text { rural area over space and time in keeping with or exceeding } \\
\text { its carrying capacity }\end{array}$ \\
\hline Endogeneity & $\begin{array}{l}\text { The degree to which rural tourism marketing promotes } \\
\text { experience and enterprise as being based on the 'real' (i.e. } \\
\text { indigenous) resources of the area }\end{array}$ \\
\hline Embeddedness & $\begin{array}{l}\text { The extent to which rural tourism marketing is engrained } \\
\text { with the ethos of the place (i.e. its politics, culture and the } \\
\text { daily routines of locals) }\end{array}$ \\
\hline Complementarity & $\begin{array}{l}\text { The degree to which a focus on complementary narratives } \\
\text { from different actor groups can enhance synergies between } \\
\text { sectors, resources or facilities even if they are not directly } \\
\text { involved in the tourism industry }\end{array}$ \\
\hline Empowerment & $\begin{array}{l}\text { The extent of control over rural tourism marketing and } \\
\text { promotion through ownership, product development or } \\
\text { planning, particularly by locals }\end{array}$ \\
\hline Sustainability & $\begin{array}{l}\text { The extent to which rural tourism marketing is capable of } \\
\text { enhancing the socio-cultural, environmental and ecological } \\
\text { well-being of a destination }\end{array}$ \\
\hline
\end{tabular}

Source: Adapted from Clark and Chabrel, 2007.

rurality as it is lived and the manner in which it is narrated. For instance, Polkinghorne (1996, pp. 365-366) explains that:

in their telling or writing, the experienced meaning of an identity story undergoes a transformation ... For experiential meaning to be expressed in language, it has to be converted into literary form and, thus, comply with the requirements of grammatical structures ... Told stories are affected by the audience to whom they are communicated ... To produce a coherent, interesting, and personally favourable tale, told stories omit details and condense parts ('flattening'), elaborate and exaggerate other parts ('sharpening'), and make parts more compact and consistent ('rationalisation') ... (Also see Cortazzi, 1993, p. 61)

Thus in capturing nuances inherent in narrated life stories, social knowledges and histories - '... how narratives work and of the work narratives do' (Loseke, 2007, p. 662) - I examine and cross-reference frames of 
references different actor groups apply in (re)imagining and (re)structuring their sociality. Also, since narrations provide the milieu for processes of 'remembering' and recollection, examining multiple perspectives on marketing of rural tourism helps in aggregating fragments of memories and assorted stories as narratives (Stewart, 1996). The very course of remembering and experiencing or in other words, '... making and remaking culture, and of navigating ['one's] ${ }^{4}$ place within it ... is a constantly unfolding process and points to ... emergent sense of agency' (Frie, 2012, p.338). Within this context rurality can be envisaged as 'created from within' - mobilised through discourse and embodying people's practical everyday life, events and their subjective experience of place. Or as Hidle et al. (2006) point out: '.. . a process, driven forward by the choices made by rural people, and the choices ... understood on the basis of the factors ... taken into account by the rural people themselves' (p. 193).

According to Labov (1982) six categories define the narrative structure, namely: (1) an outline or the gist of the event/story; (2) orientation that sets the scene situating involved actors in space and time; (3) complication or the core comprising of a sequentially ordered course of events; (4) resolution or reiteration of momentous episodes; (5) evaluation with a view to clarifying the point; and (6) a coda or generic end statement to signal the finish (cited in Goodson and Gill, 2011). Together these attributes facilitate the documentation of emerging narrative patterns, but ' . . storytelling ... is in no way determinist' (Goodson and Gill, 2011, p. 58). Each story follows its own rhythm dependent on narrators' interpretative responses to a particular issue and moderated by their personal circumstances. Further:

Narratives are seldom singular, and seldom have single versions . . . [or $\left.{ }^{5}\right]$ belong entirely to a single individual or group. Rather, they are shared ... They tell not one story, but the confluence of numerous stories, of different parts of stories, and of numerous versions. In this, they resist a linear or closed reading. (Tawa, 2002, p. 47)

Placing individual narratives within collective stories helps in integrating the individual experience within the broader socio-cultural context and underlining how rurality is experienced dialectically as a resonance between past (through shared memory) and present life stories. There is an additional reason for choosing the narrative approach as individual accounts help in capturing the imperceptible, dense web of experiences, memories and entrepreneurial opportunities rurality engenders. The overall aim is to further develop my work on IRT from a marketing perspective embedded in actors' narratives with a view to (re)theorising their 
corporeality vis-à-vis their ephemeral perceptions of a region's potential i.e. its 'real' circumstances - and its use in image building and the design of promotional strategies. Drawing upon the narrative turn in the social sciences (see Czarniawska and Gagliardi, 2003; Fisher, 1985; Maines, 1993; Reissner, 2008) the discussion focuses upon actors' storytelling and underlines how they are more likely to align with stories that cohere with their thinking and belief systems. For instance, older residents or those not directly involved in tourism are more likely to 'story' its role negatively (see Williams and Lawson, 2001) which entails that an area's potential and its carrying capacity need to be sold to them first to ensure that marketing narratives are in sync with local aspirations and a region's sense of place. By focusing on 'experience and enterprise' as two key constructs in marketing (rather, storying) rural tourism, this work endeavours to capture the juxtaposed accounts and processes involved in selling and performing rurality - i.e. 'staging the rural'.

\section{'STAGING THE RURAL'}

'Staging the rural' or consciously constructing components of rural for transaction or 'trade of value between two or more parties' (see Kotler et al., 2013) is dependent upon five key components. These are: (1) actors $^{6}$ - (producers, sellers, resource controllers, gatekeepers, facilitators, buyers and visitors); (2) products - (goods, services and ideas); (3) modalities (place, time, ownership and organisation of events and activities); (4) norms (formal and informal networking patterns and modes of actor behaviour); and (5) outcomes (visitor (dis)satisfaction and its impact on subsequent transactions and nature of actor ties). Together, they help in crafting the 'front region' of the rural (Goffman, 1959, cited in MacCannell, 1973) set aside for tourism performances and tourist experiences (Ryan and Cave, 2005) as opposed to the 'back region' denoting the destination reality. Urry (2003) critiques MacCannell's staged authenticity approach arguing that in the era of postmodernity, most tourists acknowledge the inauthenticity inherent in tourism performances; and even enact and inscribe places with their own 'stories' (Edensor, 2001). Daugstad and Kirchengast (2013) draw attention to the 'pseudo-backstage' (p. 170) that is actually the front region where the host feels in control and the guest (only the select few) is introduced to some sort of an inner realm of privacy and intimacy. Theories of liminality (see Ryan, 2011, p. 12) expound how tourists' experiences transition from being ordinary to being extraordinary dependent upon the complexity involved in packaging and presenting the product using 'place myths'. From a socio-cultural, anthropological 
perspective 'staging the rural' can be understood as a set of stylised, symbolic performances that succeed according to the skill of actors involved, the context within which they are performed and the manner in which they are interpreted by audiences (Edensor, 2006; Jafari, 2000). In phenomenonical terms, staging can be described as comprising of ritualistic performances that convey the sense of place and induce audiences to experience alternative modes of living (Chhabra et al., 2003; Turner, 1969). According to the theory of ritual practices (Huxley, 2004) tourism assumes the form of ritual performance or journey where cultural contexts are displayed to induce emotional bonding with the place and generate new dramatic experiences and configurations to convey particular values (Edensor, 2000).

Further, staging of the rural can be understood from the destination identity perspective (Zhou, 2014) implying that a destination's image - embodying tourism imaginaries or storytelling about the past that is 'value-laden, emotion-conferring collective narrative construction' (Chronis, 2012, p. 1809) - is more important than the destination itself. Narratives help in construing a place's authenticity which authors regard as a measure of the overall satisfaction of tourists resulting in longer stays or repeat visits and an enhanced interest in the 'site' (Bigne et al., 2005; Chhabra et al., 2003). Moreover, artistic and media discourses (e.g. literary works, paintings, music, film and TV productions) contribute to the commodification and aesthetic staging of rurality (Beeton, 2004, Edensor, 2007). The British television series Escape to the Country illustrates well how the deliberate performance of a rural place is managed by highlighting its attractiveness, a key indicator being people's preference for that location (Jonasson, 2012). Hence, staging involves modification and (re) configuration of cultural mores and values to suit visitors' (as well as prospective residents') tastes. On another level, it also opens up the possibility for guests to critique stereotypical images (see Chapter 5) and engage with the 'real' culture (Coleman and Crang, 2002). Also, it implies that while tourists may be self-reflexive in their quest for an authentic experience, and aware that their experiences are staged, hosts may well be equally reflexive about the images they portray and can develop tourist products and places in ways that empower them and their identities (MacDonald, 1997). Rogers' (2002) work in Monts et Barrages, France, highlights how: '. . . various hosts involved in rural tourism are no more interested in displaying local life in all its often petty, unattractive, private detail than their guests on vacation after all - are interested in experiencing it' (p. 478).

Thus, rural, as a 'community' (or the degree to which it may be said to exist), rests on its members' active participation in ongoing processes of co-production or co-constitution of carefully chosen attributes. In addition, as a result of staging, rurality is no longer a synonym for a condition 
of opposition or marginalisation relative to the modernisation processes. Zhou's (2014) study in the Wuyuan region of China reveals that rural culture and festivals are assimilated in people's daily lives (including those of urban residents) and are experienced collectively. Similarly, Cassel and Pettersson's (2015) work in rural Sweden demonstrates how the farm is transformed from being merely a site of agricultural production to a theatre where traditional rural and gender identities are simultaneously (re)produced or challenged to create particular experiences and services (Hall et al., 2003). The host performs the role of the 'culture broker' combining local cultural knowledge with personal tales and interpretations (Cohen, 1985). This phenomenon is manifest in the staging of rural festivals that: ' . . build communities out of audiences, turn residents into performers and friends, shape identity and mould experiences of rural ...'(Gibson and Connell, 2011, p. 31).

Having said this, it is worthwhile to note the struggle and feelings of ambivalence that rural residents experience (discussed in Chapter 6) as they manage tourists' interest in their community triggered by specific stimuli, 'not just an overall liking' (Brakus et al., 2009, p. 53). Also, it implies that the rurality and the marginal nature of their community fuel their intent to keep it as such or rework its economic potential by attributing a positive meaning to their subsidiary status and routine/everyday lives. Further, given the research (Aikawa-Faure, 2008; Fonneland, 2013; Sharpley and Jepson, 2011) on the spiritual element of rural tourism (hitherto considered secular), it is imperative to recognise how experiences of spirituality embodying rural communities' cultural identity are able to bring about temporal and social reordering of visitors' lives. Of particular interest is locals' view on the commercial development of the spiritual tourism experience and its marketing aimed at city dwellers and foreigners (see Chapter 5).

\section{THRUST ON EXPERIENCE}

Pine and Gilmore's (1998) seminal work on the experience economy identifies four realms of tourism experience - entertainment, education, aesthetics and escapism - arguing in favour of engaging all five senses through 'feeling, learning, being, and doing' (Mehmetoglu and Engen, 2011, p. 254). Although thrust on 'experience' cannot be considered to be an entirely new phenomenon in tourism as authors have studied the role of service quality (Parasuraman et al., 1988), satisfactory (Ryan, 1997) and quality experiences (Jennings and Nickerson, 2006; Ritchie and Hudson, 2009) in generating repeat visits, Pine and Gilmore's work has certainly given a new impetus to the study of experience as key in 
defining a 'visit' and the satisfaction tourists derive as a result. However, the emphasis on experience in tourism marketing is relatively recent (Jennings et al., 2009). From a marketing perspective, experiences can be defined as personal occurrences with high emotional significance obtained through a gamut of different degrees of engagement with a locality's attributes, products and services (Holbrook and Hirschman, 1982). In fact, recent research on the 'psychoneurobiochemistry of tourism marketing' (Koc and Boz, 2014, p. 140) underlines the need for incorporating psychological, neurological, biological and chemical research in tourism marketing to accurately gauge and enhance visitors' physiological and psychological experiences.

The emphasis now is on delivering pleasantly memorable tourism experiences and their ability to 'seduce' and satisfy consumer needs in a personalised manner (Kim, 2014; Pine and Gilmore, 2010; Pizam, 2010). According to Tung and Ritchie (2011) four dimensions that make experiences particularly memorable are affect (i.e. positive emotions), expectations (fulfilment of intentions), consequentiality (personally perceived importance derived from the outcome of the experience - enhanced social relationships, intellectual development, self-discovery and an ability to overcome challenges), and recollection (efforts to remember the tourism experience through photographs/souvenirs). Further, Schmitt (1999) distinguishes between individual experiences - sensing (aesthetics and sensory qualities), feeling (including moods and emotions), thinking (convergent/analytical and divergent/imaginative) - and shared experiences - acting (motor and behavioural actions) and relating (e.g. to a reference group) - that contribute to the generation of positive or negative emotions. Thus experiences that engage the senses (seeing, hearing, smelling, tasting and touching) plus the 'emotion-inducing' capability of marketing are key in influencing consumers' purchase decisions (Ditoiu et al., 2014).

In the context of rural tourism, experiences represent a complex construct, not only distinct from everyday life experiences (see Cohen, 1979; MacCannell, 1973), but also fulfilling urban tourists' quest for authenticity (Boorstin, 1964; Cohen, 1988), an older way of life and culture. A core aspect of rural tourism marketing is the notion of 'rural alterity' whereby 'rural is represented as being some place other than urban, as some experience other than the norm' (Hopkins, 1988, p. 78). According to Gibson and Connell (2011, p. 153):

The rural brand is most powerful when embedded in a rural location. Such a place may become so imbued with the values of the rural that it is perceived as a 'heaven on earth' or a rural utopia. A rural utopia is not only a discursive marketing tool, but also a physical reality which is able to be experienced through interaction and ultimately consumed. 
Certainly, the taglines used in marketing rural experience (see below) mobilise the rural idyll to brand and market destinations as utopias imploring visitors to undertake both physical and symbolic journeys:

'Costa Rica Dream Adventures: The natural choice'

'Visit Bhutan: Land of the Thunder Dragon'

'Cycling Colombia: The only risk is wanting to stay'

'Touch the Goodness Within' (Responsible Tourism Initiative, Kerela, India)

\section{'Get lost in Upper Hunter Country’ (Australia)}

They firmly position 'rural' as both the site and means for thinking of a life operating on a different logic through evocation of place myths like the 'Land of the Thunder Dragon', capable of delivering meaningful experiences and situating tourists as 'ethical subjects' desiring and endorsing alternative (i.e. responsible) forms of consumption. Indeed, distinctive experiences resulting from specialised forms of tourists' engagement with a place existing outside or on the periphery of everyday life have been conceptualised as 'serious leisure' (Stebbins, 2001). Studies on tourism in developing economies focus in particular on the development impacts of serious leisure and sustainable tourism and the associated potential for empowering hostcommunities (Hall and Richards, 2000; Lapeyre, 2010). Moreover, if one considers rural tourism experience as a cyclical process, gradually progressing from recreational, leisure-based experiences to momentous engagement with a locality and its attributes, visitors' role in its development and conservation becomes central. A growing body of research is beginning to focus on the co-creation process of experiences that allows individual customers to craft their own experiences through personalised interaction (with the company) resulting in better value for both (Boswijk et al., 2007; Prahalad and Ramaswamy 2003). Extending the co-creative approach to tourism Binkhorst and Dekker (2009) argue that it is likely to generate better host and guest experiences plus contribute to the product design and offer in a manner that is in sync with the essence of the place and its carrying capacity (Kastenholz and Lima, 2013). The premise is that the producer becomes a facilitator of experiences that are shaped by the creative input of tourists who are no longer just passive consumers (Prentice and Andersen, 2007). Indeed, tourists' role in co-creation is best understood in the context of postmodern landscape, characterised by the breakdown of traditional societal certainties (Roseneil, 1999) allowing travellers to shape their leisure identities and engage in the co-creation of visual, aural, olfactory, gustatory and tactile encounters (Barnes et al., 2014). Within this context, the role of rural enterprise becomes key in protracting the appeal of rural life and 
terrain despite '. . the challenges involved in sustaining these in the postindustrial context' (Rogers, 2002, p.475).

\section{RURAL ENTERPRISE}

In the context of this work, I use the term 'rural enterprise' broadly to indicate financially viable activities performed to offer or create memorable experiences for visitors and entities (businesses, community groups, non-profit-making bodies and public sector agencies) engaged in their provision. Authors point out that a shift towards place-based rural policies focusing on community needs (as opposed to those centred on the development of agriculture or other primary sectors) is most conducive to fostering rural enterprise and facilitating rural regions' access to markets and information flows in a way that is 'place appropriate' (Midmore et al., 2010). Henry and McElwee (2014, p. 5) argue that,

there is little difference between a rural and non-rural enterprise in terms of structure, that is how the business is organised or managed, or how the characteristics of the individual entrepreneur are exhibited. Thus, it would appear that there is no specific category for, nor definition of, a rural entrepreneur beyond that of 'an individual who manages a venture in a rural setting'.

However, in ascertaining the role rural enterprise plays in adding value to products and facilitating local capacity building through sustainable employment and income generation, I distinguish between three facets of rural tourism enterprise orientation (see Table 1.2, see also Chapter 4). Thus, the exogenous entrepreneurial route is characterised by reliance on extralocal markets which is in contrast to endogenous orientation that is dependent on the local ingenuity (even whim) of entrepreneurs in sustaining market interest (Table 1.2). In contrast, a neo-endogenous approach to marketing rural enterprise (manifest in LEADER ${ }^{7}$ initiatives) is inclusive and capable of balancing local needs while competing for extra-local resources.

Overall, in sustaining the momentum of rural enterprise I centralise the role of the micro-enterprise sector and its strategic linkages with high growth drivers, namely small and medium enterprises (SMEs) and large agri-businesses. Indeed, tourists are attracted by a subjective interpretation of the 'otherness' of rural places that individual entrepreneurs are able to offer (Wilson and Anderson, 2004). Besides, micro-enterprises are likely to be unconstrained by spatial peripherality and respond favourably to policies that favour innovation, sustainability and the diffusion of knowledge and learning, particularly in relation to the design and implementation of 
Table 1.2 Facets of rural tourism enterprise

\begin{tabular}{|c|c|c|c|c|}
\hline & Key focus & $\begin{array}{l}\text { Illustrative } \\
\text { examples }\end{array}$ & Challenges & Opportunities \\
\hline Exogenous & $\begin{array}{l}\text { Creation } \\
\text { of niche } \\
\text { products by } \\
\text { strengthening } \\
\text { links with } \\
\text { extra-local } \\
\text { markets }\end{array}$ & $\begin{array}{l}\text { Festivals and } \\
\text { events (Gibson } \\
\text { and Connell, } \\
2011 \text { ) }\end{array}$ & $\begin{array}{l}\text { Rural } \\
\text { dependence } \\
\text { (culturally, } \\
\text { technically and } \\
\text { economically) on } \\
\text { urban areas; as } \\
\text { a consequence } \\
\text { development } \\
\text { benefits not } \\
\text { diffused locally; } \\
\text { reliance on } \\
\text { continued } \\
\text { subsidies and } \\
\text { the policy } \\
\text { decisions of } \\
\text { distant agencies } \\
\text { (Gkartzios and } \\
\text { Scott, 2014) }\end{array}$ & $\begin{array}{l}\text { Increased } \\
\text { employment, } \\
\text { improvements } \\
\text { in technology, } \\
\text { communication } \\
\text { and } \\
\text { infrastructure } \\
\text { as well as } \\
\text { combating } \\
\text { prolonged rural } \\
\text { depopulation } \\
\text { (Woods, 2005) }\end{array}$ \\
\hline Endogenous & $\begin{array}{l}\text { Capacity- } \\
\text { building } \\
\text { (skills, } \\
\text { infrastructure } \\
\text { and } \\
\text { institutions) }\end{array}$ & $\begin{array}{l}\text { Creative } \\
\text { pursuits - } \\
\text { e.g. arts, crafts } \\
\text { (Richards and } \\
\text { Wilson, 2007) }\end{array}$ & $\begin{array}{l}\text { Limited capacity } \\
\text { of areas, } \\
\text { entrepreneurs } \\
\text { and social } \\
\text { groups to } \\
\text { participate in } \\
\text { economic and } \\
\text { development } \\
\text { activity }\end{array}$ & $\begin{array}{l}\text { Local initiative } \\
\text { and enterprise } \\
\text { can generate } \\
\text { memorable } \\
\text { experiences } \\
\text { and positive } \\
\text { publicity }\end{array}$ \\
\hline $\begin{array}{l}\text { Neo- } \\
\text { endogenous }\end{array}$ & $\begin{array}{l}\text { Place- } \\
\text { making and } \\
\text { community } \\
\text { well-being } \\
\text { through a } \\
\text { bottom-up } \\
\text { development } \\
\text { trajectory }\end{array}$ & $\begin{array}{l}\text { The LEADER } \\
\text { approach, which } \\
\text { has its origins in } \\
\text { a series of EU } \\
\text { initiatives dating } \\
\text { back to } 1991 \\
\text { delivering rural } \\
\text { development } \\
\text { at the } \\
\text { neighbourhood } \\
\text { level through } \\
\text { local initiative } \\
\text { (Ray, 2006) }\end{array}$ & $\begin{array}{l}\text { Building resilient } \\
\text { rural places } \\
\text { in the light } \\
\text { of economic } \\
\text { constraints }\end{array}$ & $\begin{array}{l}\text { Emphasis on } \\
\text { balancing local } \\
\text { needs while } \\
\text { competing } \\
\text { for extra-local } \\
\text { resources }\end{array}$ \\
\hline
\end{tabular}

Source: Author. 
creative development strategies (see Johnson and Smallbone, 2003; North and Smallbone, 2000). In fact, they draw their entrepreneurial capabilities through their relational capital that allows them to simultaneously become embedded in the region and offer emotionally enriching experiences to their clients (Jack and Anderson, 2002; Markantoni et al., 2013; Saxena, 2015).

The Rural Enterprise Development Project for Afghanistan funded by the World Bank is structured on the premise that despite low profitability, traditional specialisation and the adoption of labourintensive techniques micro-enterprises have the potential to stimulate inclusive economic growth in rural areas (IBRD, 2010). People-First Tourism (2011), described as 'a marketplace for buying and selling genuine tourism experiences' is a project supported by the North Carolina Sea Grant and the North Carolina Rural Centre that incubates networks of very small tourism businesses in economically depressed rural communities throughout North Carolina. The aim is to: 'link entrepreneurs trying to pursue dignified and sustainable livelihoods through tourism with adventurous and conscientious tourists interested in unique "off the beaten path" experiences and in making positive impacts on the communities they visit' (see http://tourism.ces.ncsu.edu/ people-first-tourism/).

Biddulph's (2015) work in Cambodia points to the presence of the 'charismatic cosmopolitan entrepreneur' (p. 110)-educated, well-travelled, mostly a return migrant - at the heart of the rural periphery as key in conjuring creative offerings and memorable experiences. Similarly, Ateljevic's (2000) work on 'lifestyle entrepreneurship' underlines the impact of rural enterprise on staged performances of rurality that are scripted and choreographed to overtly act out particular representations of local routines (see also Edensor, 2006). For instance, my research entitled 'Scarborough futures' funded by the University of Hull (2013-2014) in Yorkshire's coastal and mainly rural borough of Scarborough (including the towns of Scarborough, Bridlington, Filey and Whitby) uncovers the significant role of non-economic factors (e.g. local acuity and eccentricity) in creating 'sites of creativity'. This phenomenon is manifest in the increasingly popular annual event 'Coastival', funded mainly by the Arts Council, England and organised by Create, an arts development agency operating within the Borough of Scarborough, to offer varied experiences in performing and visual arts (see www.coastival.com). According to Dr Michelle Watts, Operations and Finance Manager, Create, Coastival aims to:

- provide access to high-quality arts and culture for Scarborough residents; 
- boost tourism in the quieter months (Coastival is held on the first weekend of the February half-term to encourage tourists to come for the weekend and stay for the week);

- put Scarborough on the cultural and festival map by improving the area's image and promoting collaboration between local arts organisations and festivals; and

- help artists and performers develop their careers.

Further, in a bid to reach remote rural areas and disadvantaged communities of North Yorkshire, Create is working with the organisers of other local events - Grassington Festival, Swaledale Festival and Harrogate International Festival - as part of the Festivals North consortium (Watts, 2015). Gladys, Coastival's 'poster girl' (see Figure 1.1) has been chosen primarily to foreground fun seaside spirit and counter the mental barriers of 'those who think "the arts" aren't for us' (ibid.). Thus the event not only establishes the viability of clusters of creative businesses and their potential in reinvigorating the image of seemingly peripheral regions, but also offers the scope to challenge the urban bias of work on 'creative clusters' (see Roodhouse, 2006; Rosenfeld, 2004). Further, it is a potent example of how rural enterprise, benefiting from the 'emotional proximity' with its customers ( $50 \%$ of the attendees are local residents) is able to engender significant economic impact (income generated over five years $-£ 2,137,780$ ) in isolated localities.

\section{CHALLENGES IN SUSTAINING RURAL ENTERPRISE}

The task of staging rural tourism is fraught with difficulties as clients' experiences and impressions are ephemeral, unpredictable and personally as well as culturally constituted (Bardone, 2013). Thus, addressing the needs of a market oriented towards inimitable and identity-forming travel products requires innovation and effort (Blekesaune et al., 2010). In addition, the success of one entrepreneur can be blighted by the failure of other enterprises and given the aging or unemployed rural population it can be extremely difficult to sustain the momentum (Bardone, 2013). Further, personal costs to the rural tourism entrepreneur (e.g. combining the emotional burden of experience-creation with daily routine) as a result of 'self-commodification'8 (Bunten, 2008) are often overlooked in the tourism literature. Despite a relative lack of competition compared to firms in urban regions, owner-managers struggle due to a lack of skills, resources (Ritchie and Crouch, 2003), limited access to finance 


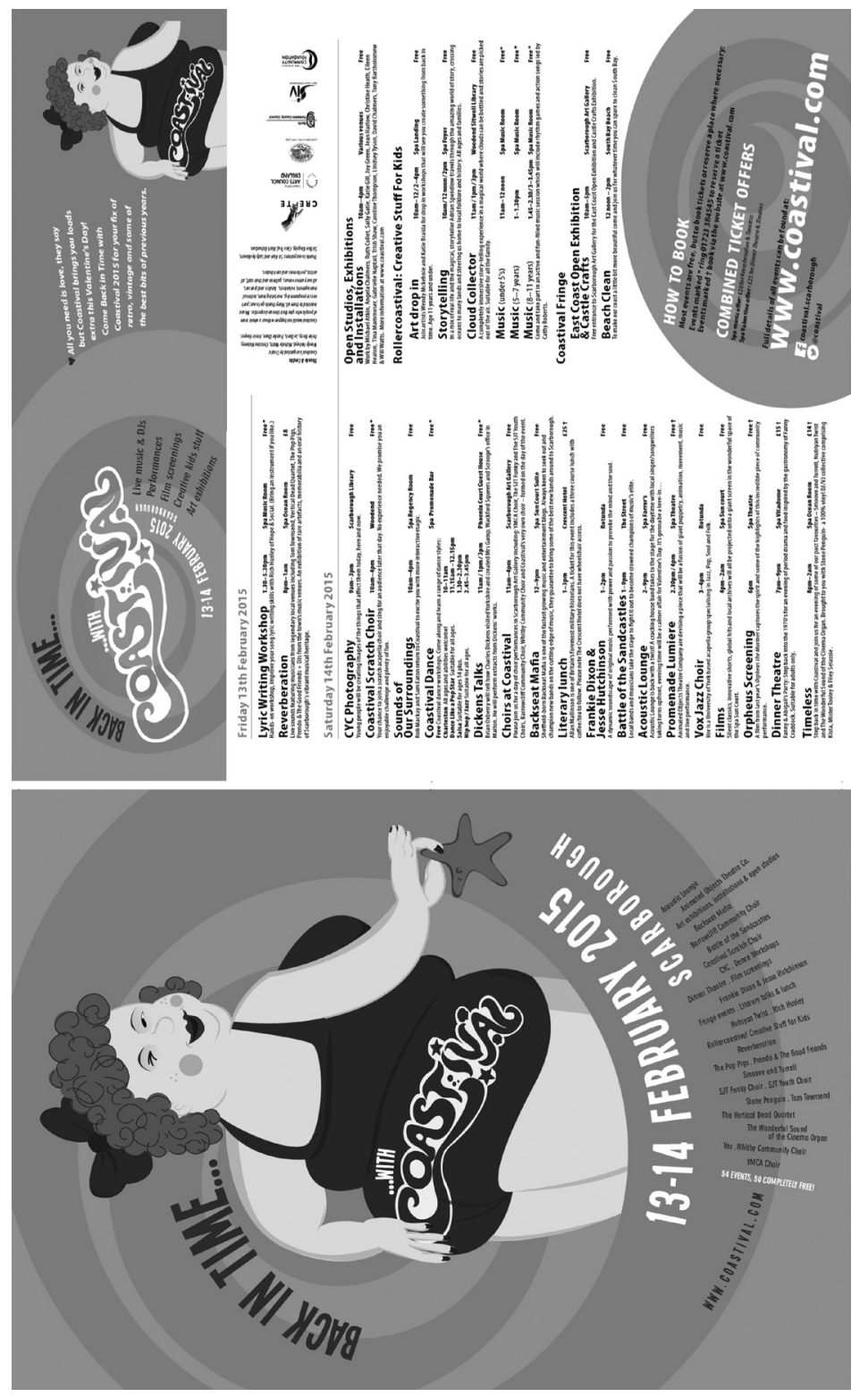

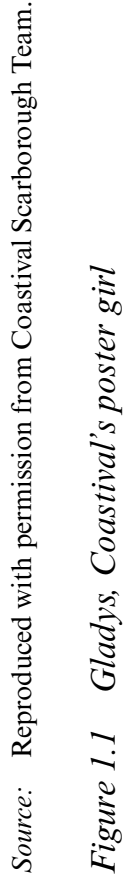


(Jarvis, 2006), Internet connectivity (Cuadrado-Roura et al., 2004; Sanders and Galloway, 2013) and an unfair institutional regulatory environment inhibiting business growth (Smallbone and Wyer, 2006). Parallel trends of the decline and closure of rural retail units are evident in Europe and the USA (Miller, 2001; Paddison and Calderwood, 2007). Crucially, the market logic, in being urban and commerce-biased, perpetuates indigenous peoples' exclusion (Maclean, 2013; Saxena and Singh, 2014). Indeed, developing the entrepreneurial skills of farmers was one of the Third Call tasks in the 6th Research Framework Programme of the European Union (2002-2006) that acknowledged the role of socio-cultural and economic factors, including educational processes in constraining farmers' ability to successfully develop their enterprise (EU, 2002). Additionally, crisis management as a strategy is absent from the day-to-day running of a farm or a rural tourism enterprise as a crisis event may have to occur before crisis planning becomes a real concern (Spillan and Hough, 2003). For instance, the foot-and-mouth crisis in Britain in 2001:

proved a classic example of how to turn a crisis into a fully-fledged copperbottomed disaster. It meant the deaths of nearly four million animals in the UK, and destroyed thousands of farmers' livelihoods ... The Countryside Agency put the cost to UK farming in 2001 at between $£ 800 \mathrm{~m}$ and $£ 2.4 \mathrm{bn}$. The cost to tourism, it reckoned, was between $£ 2$ bn and $£ 3$ bn this year. (Alex Kirby, BBC News, Friday 28 December 2001)

Moreover, rural localities face atypical issues. A range of studies have raised concern for the social and environmental health of rural communities that are reported to be stagnating/declining (Bontje and Musterd, 2012) and facing problems of socio-economic isolation (Erickson et al., 2012), outmigration (Rees et al., 1997) of locals on one hand and in-migration of a post-industrial middle class (mostly in developed economies) to 'amenityrich' rural areas, a process described as rural gentrification (Hines, 2012, p. 74), exacerbating pre-existing social, geographic and environmental disparities. Further, low demand for and lack of access to services and goods (Sharpley, 2002) result in incidents of poor physical and mental health (Bourke et al., 2012). Thus 'rural' as a place/environ lacks the romanticised stability and solidity often assumed in humanistic discourse, but is rather restrictive ambit saddled with lack of opportunities and choice. However, rural enterprise, despite insignificant political clout and constrained by small scale and scope, is able to mobilise these very qualities to create unique tourism experiences in marginal regions as is evident in El Alberto (located in the municipality of 1xmiquilpan) in Mexico's Valle del Mezquital region. In addition to possessing private lands, residents (who are a part of the ethno-linguistic group known as $\mathrm{Otomi}^{9}$ ) observe 
collective landownership that has formed the basis of Parque EcoAlberto, a unique ecotourism venture that provides the backdrop for the staging of the Caminata Nocturna (night hike), a simulation of the experience of crossing the US-Mexico border as an illegal migrant (Figure 1.2). Tour guides like Raul de Mario, ${ }^{10}$ (former illegal migrant to the US along with others like him) regularly stage the Caminata Nocturna, transforming memories of migration into saleable commodity. Serat's (2010) research in the region confirms how in a bid to offer sustainable alternatives to migration and generate employment, migrants like him have: '. . taken the ugliness of the border - the violence and indignity of encounter with Border Patrol agents, the dull ache of thirst, the threat of death - and transformed it into ... [a] product' (p. 35).

Thus on one hand, EcoAlberto offers Raul and his colleagues (Antonio and Maria, both in their twenties who I interviewed at the Park), an opportunity to commodify their peculiar personal circumstances and derive a sense of pride from running the enterprise. On the other, it serves as temporary interlude for them as they await their chance, to emigrate to the US with the help of coyote (paid guides who know the track and are at times, I was informed, even able to strike a deal with the US border patrol agents). Antonio questioned my motive for being in EcoAlberto and was quite sceptical about the inclusion of his story in my book. He continued, reiterating: 'Yes, but what is in it for me? Why my story matters to you or for that matter to your readers?' Maria added: 'My story in your book, it cannot buy me a US visa or a better life here'. Given these accounts, I wonder if Antonio and Maria, in the process of staging the Caminata Nocturna and experiencing the horrors of border-crossing, have already moved across subconsciously whilst they wait for the opportune moment to transgress and traverse it physically.

EcoAlberto is marketed as 'A park in Mexico [which] offers all the experiences of an illegal border crossing except for one: the border' on Atlas Obscura, an online travel guide for 'the world's wondrous and curious places' (www.atlasobscura.com). Thus rural enterprise (drawing upon the flesh and blood experiences of entrepreneurs) as this example illustrates serves as a medium through which the disempowered are able to acquire agency and transcend margins in space and time (Tweed, 2006). Also, rather than transforming rural areas into 'virtual' areas (i.e. disconnected from reality as authors suggest, see Figueiredo and Raschi, 2012; Halfacree, 2007), commodification of real-life stories offers the possibility to residents not only to retain a sense of self, but also to embark upon endogenous forms of development that are embedded in their immediate contexts. 

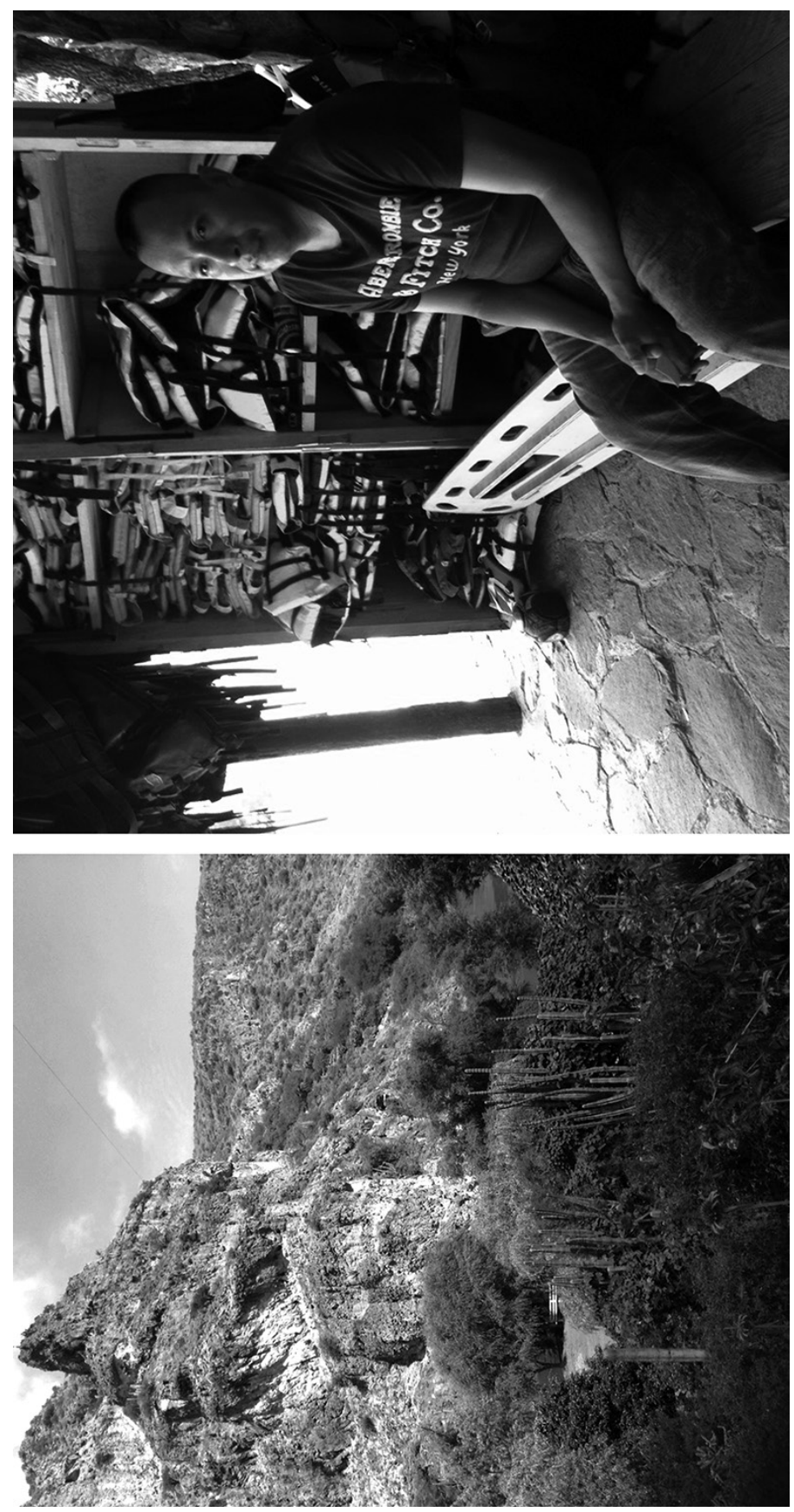

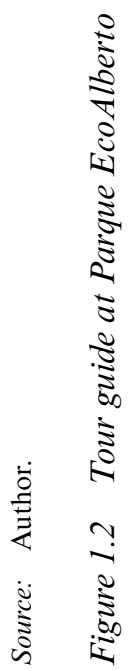




\section{RURALITY AS A CHOICE}

Rurality as a development choice (see Chigbu, 2013) entails an engagement with Gibson-Graham's (2006, p. xxvii) '. . . ontology of a politics of possibility ...' embodying in situ identities, material resources and structures capable of empowering rural communities. Ateljevic's (2009) study on women entrepreneurs in the Wirarapa region of New Zealand demonstrates clearly how their enterprise is steering it away from the regional rural culture and long-standing farming tradition towards creative and cultural forms of rural tourism. In poststructuralist terms, the role of rural enterprise in engendering empowering identities based on rural components, can be understood as a process of 'cultivating contemporary forms of subjectivity' (Cameron and Gibson, 2005). In transition economies like Russia and China, turbulence and uncertainty have proved ideal for sustaining the creative energy and dynamism of rural entrepreneurship, well documented in the special editions of the Journal of Small Business and Enterprise Development in 2006 and 2008 on Chinese entrepreneurship (also see Hall et al., 2006 for studies on tourism enterprise in Eastern Europe).

Thus the next chapter will focus on instances that provide the opportunity for (re)imagining rurality taking into account the development discourse which calls for tending rural areas in a manner that makes rural lives and the environment sustainable, while preserving their identities. It will outline the process underlying the construction of rurality (albeit pseudo rurality) as a possible choice (as opposed to urbanity or modernisation) in marketing rural tourism. In particular, in the ensuing discussion my focus will be on factors that are challenging the established notions of rurality, discussed in the influential works of Paul Cloke and colleagues (e.g. Cloke, 1977, 1978; Cloke and Edwards, 1986), to explore the impact of the marketing of the rural tourism experience and enterprise on two key dimensions of rurality - structural and demographic. Whilst structural rurality represents the physical aspects of rurality (e.g. high percentage of agriculture employment, greater distance from urban conurbations, but better amenities, greater commuting population and higher population density signifying decline in rurality), demographic rurality draws on both the elderly and the fertile populations as key indicators (e.g. the older the population the more rural, while the more women of childbearing age the more urban the setting (see Harrington and O'Donoghue, 1998)). Overall, the discussion centres upon different facets of 'rurality in flux' and the multifarious manner in which they are utilised for tourism. 


\section{NOTES}

1. It implies that actors experience rurality in qualitatively different ways and interpret meanings 'in relation to their personal circumstances (e.g. capabilities, expectations and memories) and their social-cultural contexts (e.g. social roles, cultural practices and historical conditions) . . . because individuals never stop experiencing themselves and the world, meanings are potentially multiple and inexhaustible ...'(Watkins and Bond, 2007, p. 291).

2. I borrow these terms - dominant, residual and emergent - from Raymond Williams' work Marxism and Literature (1977) where he uses them to conceptualise culture. Thus dominant represents practices, meanings and value that prevail as the norm, residual denotes the remnants of the past that are still active in shaping the place character and its culture, whilst emergent elements signify new meanings and values, practices and associations (Williams, 2005). These conceptual tools enable an identification of strands of continuity and change structuring rural landscapes.

3. It is to be noted that interpretation of narratives requires that attention is given to not only 'what is said, but also verbal expression. The intonation in the participant's voice provides important clues to the bodily effects of listening' (Waitt and Duffy, 2010, p. 465).

4. Italics are my own.

5. Italics are my own.

6. See Saxena and Ilbery (2010) for a definition of key rural tourism actors and the roles they perform in staging the rural.

7. The acronym LEADER derives from the French Liaison Entre Actions de Développement de l'Économique Rurale, which means 'Links between the rural economy and development actions' (see http://enrd.ec.europa.eu/enrd-static/leader for details).

8. Self-commodification can be defined as a set of beliefs and practices in which an individual chooses to construct a marketable identity by exploiting one's social background to create a commercially appealing image, while striving to retain a sense of self (Bunten, 2008).

9. Since the 1980s, 'hñahñus' has become the preferred term of self-reference as Otomi was a disparaging term used by outsiders (Serat, 2010).

10. All respondents' names used in the book are pseudonyms. 